\title{
Foetomaternal outcome in multifoetal pregnancy in a tertiary rural teaching hospital
}

\author{
Sneha Gond, Partha Pratim Sharma*, Narra Madhuri, Kasturi Barman
}

Department of Gynaecology and Obstetrics, Midnapore Medical College, Paschim Medinipur, West Bengal, India

Received: 03 December 2020

Accepted: 05 January 2021

\section{*Correspondence:}

Dr. Partha Pratim Sharma,

E-mail: parthap_sharma@yahoo.co.in

Copyright: () the author(s), publisher and licensee Medip Academy. This is an open-access article distributed under the terms of the Creative Commons Attribution Non-Commercial License, which permits unrestricted non-commercial use, distribution, and reproduction in any medium, provided the original work is properly cited.

\begin{abstract}
Background: Aim of the study was to find out foeto-maternal outcome of multifoetal pregnancy in relation to chorionicity and to analyse the associated risk factors.

Methods: This study was a prospective observational study on multifoetal pregnancy conducted at Midnapore medical college and hospital. Statistical analysis was done by chi-square test and statistical significance was set at pvalue $<0.05$.

Results: Incidence of multifoetal pregnancy was 1.7\%. Modal age group was 20-24 years age and $82 \%$ conceived spontaneously. Among chorionicity, Dichorionic diamniotic (DCDA) were 60\% followed by 34\% Monochorionic diamniotic (MCDA), 4\% Monochorionic monoamniotic (MCMA) and 2\% Trichorionic triamniotic (TCTA). Among maternal complications preterm labour were present in both twins and triplets followed by anemia. LSCS was required in $60.8 \%$ of twins and common indication was malpresentation. Majority of MC and TC were delivered at gestational age of 31-33 weeks (47.1\% MCDA, 50\% MCMA and 60\% TCTA) and dichorionic delivered at 34-36 week (48.7\%). Statistical association between neonatal outcomes and chorionicity were significant in IUGR $(\mathrm{p}=<0.0001)$, stillbirth $(\mathrm{p}=0.0356)$, congenital anomalies $(\mathrm{p}=0.0017)$, discordant growth $(\mathrm{p}<0.0001)$, Apgar score $<7$ $(\mathrm{p}<0.0001)$, low birth weight $(\mathrm{p}=0.014)$, live birth $(\mathrm{p} \leq 0.0001)$ and NICU admission $(\mathrm{p}<0.0001)$.

Conclusions: Maternal and perinatal outcome was significant in monochorionic and trichorionic pregnancies compared to dichorionic pregnancies with increased NICU admissions required in monochorionic and trichorionic gestations.
\end{abstract}

Keywords: Chorionicity, Foetomaternal outcome, Multifoetal pregnancy, Twin and triplet pregnancy

\section{INTRODUCTION}

Incidence of monozygotic twins is uniform throughout the world as 3.5 per 1,000 live birth and dizygotic twins varies between 50 per 1,000 live births and triplets approximately 1 per 7,000 to 10,000 birth as it is affected by multiple factors such as use of assisted reproductive technology, ethnic differences and maternal age. ${ }^{1}$

Twining is a result of fertilization of two separate ova (dizygotic) and one-third of cases arises from division of a single fertilized ovum into two separate embryo (monozygotic). ${ }^{2}$ Globally incidence is found in subSaharan Africa with average twining rate of 20 per 1,000 deliveries and in Europe and Asia it is around 5-6 per 1,000 deliveries. ${ }^{3,4}$

Multifoetal pregnancy is considered as high risk pregnancy. In India, twining occur approximately $1 \%$ of all pregnancies and has been reported to be responsible for $10 \%$ of all perinatal mortality. ${ }^{5}$

Multifoetal gestation though accounting for only a lesser percentage of live births, are known to account for a 
disproportionate percentage for all the adverse obstetric and perinatal complications. Chorionicity is an important determinant of perinatal outcome in multifoetal pregnancy. Risk of complications are $15-20 \%$ more in monochorionic than dichorionic twins. ${ }^{6}$ Objective was to study the foetomaternal outcome in relation to chorionicity.

\section{METHODS}

This prospective observational study included 250 women with multifoetal pregnancy, over a period of 1 year, admitted for delivery in the department of obstetrics and gynecology at Midnapore medical college and hospital in collaboration with Department of Pediatrics, Anesthesia and Critical care unit. We have blood bank facility and neonatal intensive care unit (NICU) facility present in this hospital.

\section{Inclusion criteria}

All women with multifoetal pregnancies, 28 weeks or more, diagnosed by clinical or ultrasonography, mothers with multifoetal pregnancy admitted for confinement were included in the proposed study.

\section{Exclusion criteria}

Those who have not given consent, women with preexisting medical disorder like chronic hypertension, diabetes, cardiac diseases, renal disease or collagen vascular diseases were excluded from the study.

Detailed obstetric history, family history of multifoetal pregnancy, intake of ovulation induction agents were taken. A general physical examination was done to note the associated complications like anemia, hypertension, and jaundice. Per abdominal and pelvic examination were also done. Data regarding maternal and neonatal parameters including demographic details, history, antepartum and intrapartum complications, neonatal outcomes and perinatal mortality were taken. Placental examination done to confirm the chorionicity. Details of mode of delivery, gestational age at the time of delivery, birth weight and Apgar score were noted. Congenital malformation was determined by sonography during pregnancy as well as by careful examination of the newborn baby. Incidence of postpartum hemorrhage were also noted. Both the mother and the babies will be followed up until discharge from the hospital or 7 days postpartum.

Statistical analysis were done using SPSS for Windows (version 22). Chi square test was used as test of significance with p-value $<0.05$

\section{RESULTS}

There were 250 multifoetal deliveries during the study period. Out of which 245 were twin deliveries and 5 were triplets. The incidence of multifoetal pregnancy in present study was found to be $1.7 \%$.

Table 1: Demographic and obstetric characteristics of study population $(\mathrm{N}=\mathbf{2 5 0})$.

\begin{tabular}{|lll|}
\hline Characteristics & Number & Percentage \\
\hline Maternal age (years) & & \\
\hline$<20$ & 61 & 24.4 \\
\hline $20-24$ & 96 & 38.4 \\
\hline $25-29$ & 68 & 27.3 \\
\hline $30-34$ & 19 & 7.6 \\
\hline $35-39$ & 6 & 2.4 \\
\hline Gravida & & \\
\hline Primigravida & 105 & 42 \\
\hline Multigravida & 145 & 58 \\
\hline Pre- gestational BMI & & \\
\hline$<18.5$ & 20 & 8 \\
\hline $18.5-24.9$ & 75 & 30 \\
\hline $25-29.9$ & 147 & 59 \\
\hline$\geq 30$ & 8 & 3 \\
\hline Booked status & & \\
\hline Booked & 175 & 70 \\
\hline Unbooked & 75 & 30 \\
\hline Mode of conception & & \\
\hline Spontaneous & 204 & 81.6 \\
\hline Drug induced & 37 & 14.8 \\
\hline IUI & 9 & 3.6 \\
\hline Family history & & \\
\hline Present & 20 & \\
\hline Absent & 230 & \\
\hline & & \\
\hline
\end{tabular}

Maximum number of women $(38.4 \%)$ belonged to age group of 20-24 years. Majority of the mothers were multigravida $(58 \%)$ and were booked $(70 \%)$ and had pre gestational BMI of 25-29.9 (59\%) i.e., overweight category. $81.6 \%$ of mothers had spontaneous conception. However, $14.8 \%$ conceived after ovulation induction. Family history of multifoetal pregnancy was found in $8 \%$ of women.

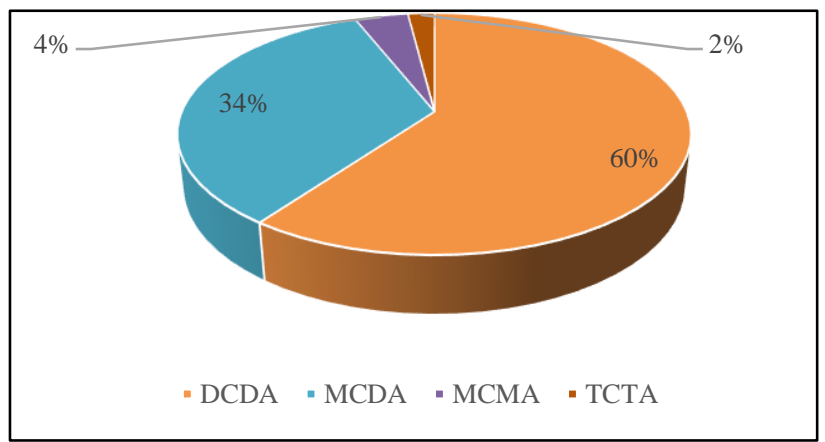

Figure 1: Type of chorionicity.

In multifoetal pregnancy, among twins maximum were dichorionic diamniotic and among triplets it was trichorionic triamniotic only. 
Table 2: Pregnancy complications $(\mathrm{N}=250)$.

\begin{tabular}{|llllll|}
\hline Complications & $\begin{array}{l}\text { Monochorionic } \\
(\mathbf{N = 9 5})\end{array}$ & $\begin{array}{l}\text { Dichorionic } \\
(\mathbf{N = 1 5 0})\end{array}$ & $\begin{array}{l}\text { Trichorionic } \\
(\mathbf{N = 5})\end{array}$ & $\begin{array}{l}\text { Chi square value } \\
(\boldsymbol{2} \mathbf{2})\end{array}$ & P value \\
\hline Gestational hypertension & $3.15 \%$ & $6.66 \%$ & $40 \%$ & 12.03 & 0.0024 \\
\hline Pre eclampsia & $17.89 \%$ & $6.66 \%$ & $20 \%$ & 7.77 & 0.02 \\
\hline GDM & $1.05 \%$ & $6.66 \%$ & $20 \%$ & 6.59 & 0.037 \\
\hline Abruptio placentae & $3.15 \%$ & $2.66 \%$ & $40 \%$ & 19.51 & 0.0005 \\
\hline Placenta previa & $2.10 \%$ & $2.1 \%$ & $20 \%$ & 6.74 & 0.034 \\
\hline Anemia & $10.5 \%$ & $20.5 \%$ & $60 \%$ & 12.78 & 0.0016 \\
\hline Preterm & $21.05 \%$ & $40 \%$ & $60 \%$ & 11.07 & 0.039 \\
\hline PROM & $10.52 \%$ & $6.66 \%$ & $20 \%$ & 7.27 & 0.264 \\
\hline PPROM & $16.8 \%$ & $6.66 \%$ & $20 \%$ & 6.85 & 0.032 \\
\hline PPH & $21.05 \%$ & $16 \%$ & $60 \%$ & 6.64 & 0.036 \\
\hline
\end{tabular}

As shown in Table 2, preterm delivery was found to be the commonest complication $(21.05 \%$ in monochorionic, $40 \%$ in dichorionic and $60 \%$ in trichorionic). Anemia was more common in dichorionic $(20.5 \%)$ and trichorionic (60\%) pregnancies. Although PPH was one of the leading conditions complicating in monochorionic $(21.05 \%)$ and trichorionic $(60 \%)$, its incidence was slightly lower in dichorionic pregnancy $(16 \%)$.

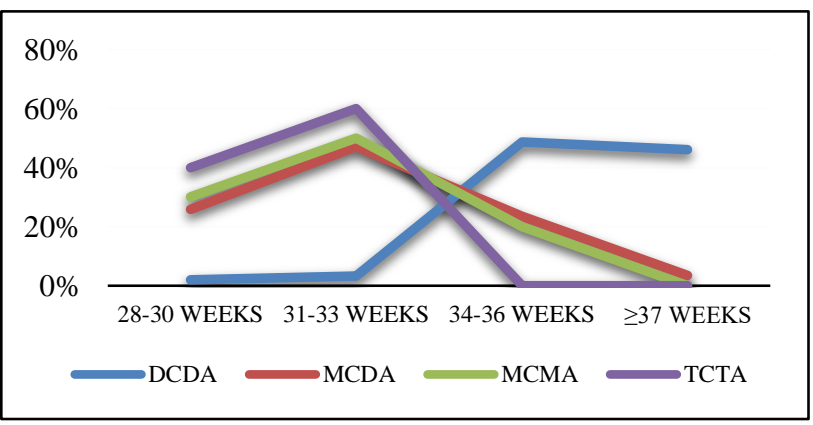

Figure 2: Gestational age at delivery in relation to chorionicity $(\mathrm{N}=\mathbf{2 5 0})$.

The gestational age at delivery in present study for monochorionic and trichorionic pregnancy was 31-33 weeks (47.1\% MCDA, 50\% MCMA and 60\% TCTA) whereas for dichorionic pregnancy it was 34-36 weeks (48.7\%) (Figure 2).
Table 3: Mode of delivery ( $\mathrm{N}=250)$.

\begin{tabular}{|ll|l|}
\hline Mode of delivery & Twins $(\mathbf{n = 2 4 5})$ & Triplets $(\mathbf{n}=\mathbf{5})$ \\
\hline LSCS & $60.8 \%$ & $20 \%$ \\
\hline Vaginal & $31.4 \%$ & $80 \%$ \\
\hline Vacuum extraction & $3.26 \%$ & - \\
\hline $\begin{array}{l}\text { Combined } \\
\text { (vaginal + LSCS) }\end{array}$ & $2.44 \%$ & - \\
\hline Forceps & $2.04 \%$ & - \\
\hline
\end{tabular}

Most of the triplets delivered vaginally and $20 \%$ by LSCS, whereas $60.8 \%$ of twin delivered by LSCS, most common indication for LSCS was malpresentation, $31.4 \%$ delivered vaginally, vacuum extraction (3.26\%), combined vaginal + LSCS $(2.44 \%)$ and forceps were required in $2.04 \%$ of deliveries as shown in Table 3.

LBW was the commonest adverse neonatal outcome seen (monochorionic $84.7 \%$, dichorionic $74 \%$ and trichorionic $86.7 \%$ ) followed by Apgar score $<7$ at 5 mins (monochorionic $81.4 \%$, dichorionic $40 \%$ and trichorionic $73.3 \%)$. NICU admission was twice higher in monochorionic (61.6\%) and trichorionic (59.9\%) compared to dichorionic (34.3\%) pregnancy. Dichorionic pregnancy also scored better in terms of live births $(85 \%)$ than monochorionic (67.9\%) and trichorionic $(33.3 \%)$ pregnancies.

Table 4: Neonatal outcome in relation to chorionicity $(\mathrm{N}=505)$.

\begin{tabular}{|c|c|c|c|c|c|c|}
\hline \multicolumn{2}{|c|}{ Neonatal outcome } & $\begin{array}{l}\text { Monochorionic } \\
(\mathrm{N}=190)\end{array}$ & $\begin{array}{l}\text { Dichorionic } \\
(\mathrm{N}=\mathbf{3 0 0})\end{array}$ & $\begin{array}{l}\text { Trichorionic } \\
(\mathrm{N}=15)\end{array}$ & $\begin{array}{l}\text { Chi square } \\
\text { Value }\left(\chi^{2}\right)\end{array}$ & P value \\
\hline \multicolumn{2}{|l|}{ IUGR } & $10 \%$ & $3.3 \%$ & $53.3 \%$ & 55.8 & $<0.0001$ \\
\hline \multicolumn{2}{|l|}{ Still birth } & $5.3 \%$ & $2.3 \%$ & $13.3 \%$ & 6.67 & 0.0356 \\
\hline \multicolumn{2}{|c|}{ Congenital anomalies } & $6.8 \%$ & $1 \%$ & $6.7 \%$ & 12.72 & 0.0017 \\
\hline \multicolumn{2}{|c|}{ Discordant growth } & $8.4 \%$ & $2.7 \%$ & $46.7 \%$ & 50.76 & $<0.0001$ \\
\hline \multicolumn{2}{|c|}{ Apgar score $<7$} & $81.1 \%$ & $40 \%$ & $73.3 \%$ & 81.54 & $<0.0001$ \\
\hline \multicolumn{2}{|c|}{ Low birth weight $(<2.5 \mathrm{~kg})$} & $84.7 \%$ & $74 \%$ & $86.7 \%$ & 8.54 & 0.014 \\
\hline \multicolumn{2}{|l|}{ Live birth } & $67.9 \%$ & $85 \%$ & $33.3 \%$ & 35.92 & $<0.0001$ \\
\hline \multirow{3}{*}{$\begin{array}{l}\text { NICU } \\
\text { admission }\end{array}$} & 1-5 days & $13.2 \%$ & $19.3 \%$ & $13.3 \%$ & \multirow{3}{*}{36.18} & \multirow{3}{*}{$<0.0001$} \\
\hline & $6-15$ days & $32.6 \%$ & $13 \%$ & $13.3 \%$ & & \\
\hline & 16-30 days & $15.8 \%$ & $2 \%$ & $33.3 \%$ & & \\
\hline
\end{tabular}




\section{DISCUSSION}

In the present study, incidence of multifoetal pregnancy was found to be $1.7 \%$ which is similar to the study reported by Ri-Na-Su et al. ${ }^{7}$ In another study from U.S.A it was reported as $1.2 \%$ whereas a study from Nigeria reported a much higher incidence (32.5 per 1000 deliveries). This discrepancy in different studies may be due to differences in the genetics, age of marriage and conception in different regions. ${ }^{8,9}$

Majority of the mothers in this study were multigravida, with modal age group of 20-24 years age, with $8 \%$ positive family history of multifoetal pregnancy which is similar to the study reported by Purnima Upreti except that in her study $70 \%$ were unbooked (Table 1). This difference could be due to our being a tertiary care hospital so most of these multifoetal gestation cases were referred from different centers for better management of complications associated with multifoetal pregnancy. ${ }^{10}$ Figure 1, showing distribution of chorionicity in present study. DCDA was common among twins. Assuncao et al conducted in 289 twin pregnancies noted incidence of chorionicity similar to present study. ${ }^{11}$ In triplets, TCTA was $100 \%$ similar to the study by Ranjan et al with most common chorionicity being TCTA as $83 \% .^{12}$

Gestational hypertension, pre-eclampsia, GDM, Abruptio placentae, placenta previa, anemia, preterm labour, PROM, PPROM and PPH were significant in relation to chorionicity. Among which gestational hypertension, abruptio placentae and anemia were highly significant in relation to chorionicity (Table 2). More than one complication was found in few multifoetal pregnancies in the present study. Other studies also reported higher incidence of obstetrical complications with multifoetal pregnancies with preterm labour and anemia were common complications. ${ }^{13}$

Figure 2 shows majority of monochorionic and trichorionic gestations were delivered before 34 weeks whereas dichorionic gestations were delivered after 34 weeks. A study by Assuncao et al reported similar observation where most deliveries in monochorionic pregnancies took place at 31-33 weeks and in dichorionic pregnancies at 34-36 weeks of gestation. ${ }^{11}$ Among trichorionic pregnancies, $60 \%$ were delivered at 31-33 weeks which is similar to that reported by Ranjan et al, where more than $60 \%$ delivered before 34 weeks. ${ }^{12}$ Hence it was inferred that the gestational age at delivery was lower in monochorionic and trichorionic pregnancies compared to dichorionic pregnancies.

Majority of twins were delivered by LSCS as shown in Table 3, where malpresentation was the commonest indication for LSCS which is similar to the observation reported by Nimbalkar et al. ${ }^{14}$ In triplet pregnancy, maximum mothers were admitted with early labour and trial of labour tried and $80 \%$ had successful vaginal delivery while one mother underwent for LSCS due to breech presentation. The present study was similar to Alran et al done in Paris, where $71 \%$ were delivered vaginally. ${ }^{15}$

In Table 4, neonatal outcome in terms of IUGR, stillbirth, congenital anomalies, discordant growth, Apgar score $<7$ at 5 mins, low birth weight, live birth, NICU admission in relation to chorionicity was studied and all were found to be significant. Singh et al and Alran et al also reported the same. ${ }^{16,15}$ In present study, congenital anomalies were found significant $(\mathrm{p}=0.0017)$ in trichorionic gestations compared to mono and dichorionic gestations, Kernberg et al reported similar findings $(27.5 \%$ vs $11.8 \%$ with $\mathrm{p}<0.001) .{ }^{17}$ IUGR was more in triplet $(53.3 \%)$ whereas in other studies it is reported very low $(11.9 \%) .{ }^{18}$ This could be explained by distribution of triplet gestation was small in number in present study. Trichorionic babies required more NICU stay (16-30 days) compared to dichorionic babies (1-5 days).

\section{Limitations}

First, the sample size of our study was small. Only 250 participants are not sufficient for this kind of study. The study needs to be conducted on a larger scale to obtain more clinically and statistically significant outcomes. Second, this was a tertiary level hospital based, singlecentered study so the results may not reflect the whole community. Third, randomized control trial or cohort study will give cause and effect relation more precisely.

Nevertheless, this study has left scope for a future research in these topics with community-based studies with larger sample size. Preterm labour and anemia were found to be complicating majority of multifoetal pregnancies giving rise to adverse outcomes. Hence, addressing for the provision of better antenatal care and NICU facilities keeping in mind the high risks, which a multifoetal pregnancy carries will ultimately result in better maternal and neonatal outcomes in the long run.

\section{CONCLUSION}

Maternal and perinatal outcome was significant in monochorionic and trichorionic pregnancies compared to dichorionic pregnancies. Increased NICU admissions required in monochorionic and trichorionic gestations than dichorionic gestations.

Funding: No funding sources

Conflict of interest: None declared

Ethical approval: The study was approved by the Institutional Ethics Committee

\section{REFERENCES}

1. Echeverry CJ. Multiple Gestation. In: Arias F, Daftary SN, Bhide AG (Eds). Practical guide to high risk pregnancy and delivery a south Asian 
perspective, 3rd edition. New Delhi: Elsevier. 2008:293-322.

2. Yayla M, Rahime N, Baytur Y. Multientric multiple pregnancy studt iii: triplets. Perinatal J. 2010;18(1):494-8.

3. Obiechina NJ, Okolie VE, Eleje GU, Okechukwu ZC, Anemeje OA. Twin versus singleton pregnancies: The incidence, pregnancy complications and obstetric outcome in a Nigerian tertiary hospital. Int J Women Health. 2011;3:22730.

4. Yasmeen N, Aleem M, Iqbal N, Maternal and fetal complications in multiple pregnancies. Ann K Ed Med Coll. 2006;12:512-4.

5. Gupta D, Mital P, Meena BS, Benwal D. Comparitive assessment of fetomaternal outcome in twin pregnancy with singleton pregnancy at tertiary care cenre. Int J Reprod Contracept Obstet Gynecol. 2017;6(6):2395-400.

6. Carroll SG, Tyfield L, Reeve L, Porter H. Is zygosity or chorionicity the main determinant of fetal outcome in twin pregnancies?. Am J Obstet Gynecol. 2005;193(3):757-61.

7. Su RN, Zhu WW, Wei YM, Wang C, Feng H, Lin L et al. Maternal and neonatal outcome in multiple pregnancy: a multicentre study in the Beijing population. Chronic Dis Trans Med. 2015;1(4):197202.

8. Usta IM, Nassar AH, Awwad JT, Nakad TI, Khalil AM, Karam KS. Comparison of the perinatal morbidity and mortality of the presenting twin and its co-twin. J Perinatol. 2002;22(5):391-6.

9. Akaba GO, Agida TE, Onafowokan O, Offiong RA, Adewole ND. Review of twin pregnancies in a tertiary hospital in Abuja, Nigeria. J Health Popul Nutr. 2013;31(2):272-7.

10. Upreti P. Twin pregnancies: incidence and outcomes in a tertiary health centre of Uttarakhand, India. Int J
Reprod Contracept Obstet Gyncol. 2018;7(9):3250525.

11. Assuncao RA. Perinatal outcome of twin pregnancies delivered in a teaching hospital. Rev Assoc Med Bras. 2010;56(4):447-51.

12. Ranjan P, Srinivas M, Vavilala P, Surubhotla N. Maternal and early perinatal outcomes of triplet pregnancy: study of 82 triplets from a single perinatal centre in south India. J Obst Gynecol India. 2018;68(3):179-84.

13. Asalkar M, Kasar B, Dhakne S, Panigrahi PP. Study of perinatal outcome in twin gestation in rural referral hospital in Maharashtra (India): a cross sectional study. Int $\mathrm{J}$ Reprod Contracept Obstet Gynecol. 2017;6:5074-80.

14. Nimbalkar PS, Bava A, Nandanwar Y. Study of maternal and foetal outcome in multifoetal pregnancy. Int J Reprod Contracept Obstet Gynecol. 2016;5(10):3478-81.

15. Alran S, Sibony O, Luton D. Maternal and neonatal outcome of 93 consecutive triplet pregnancies with $71 \%$ vaginal delivery. Acta Obstet Gynecol Scand. 2004;83:554-9.

16. Singh L, Trivedi K. Study of maternal and fetal outcome in twin pregnancy. Int J Reprod Contracept Obstet Gynecol. 2017;6:2272-8.

17. Annessa K, Teresa S, Brian S, Richard B. Congenital anomalies in twin versus triplet pregnancies. Am J Obst Gynecol. 2016;214:S163-4.

18. Downing M, Sulo S, Parilla B. Perinatal and neonatal outcomes of triplet gestations based on chorionicity. Am J Perinatol Rep. 2017;7:e59-e63.

Cite this article as: Gond S, Sharma PP, Madhuri N, Barman K. Foetomaternal outcome in multifoetal pregnancy in a tertiary rural teaching hospital. Int $\mathbf{J}$ Reprod Contracept Obstet Gynecol 2021;10:614-8. 